\title{
ANALISIS LAJU ALIRAN MASSA FLUIDA DINGIN TERHADAP EFEKTIVITAS PENUKAR KALOR SHELL AND TUBE DESTILLASI MINYAK ATSIRI CENGKEH (Syzygium aromaticum )
}

\author{
Rengga Said ${ }^{1, *}$, Nicolas Titahelu ${ }^{2}$, Rikhard Ufie ${ }^{3}$ \\ 1Jurusan Teknik Mesin Fakultas Teknik Universitas Pattimura, Ambon, 97233 \\ *Email: defoe20ad@gmail.com \\ 2Jurusan Teknik Mesin Fakultas Teknik Universitas Pattimura, Ambon, 97233 \\ Email: titahelun@gmail.com \\ 3Jurusan Teknik Mesin Fakultas Teknik Universitas Pattimura, Ambon, 97233 \\ Email: rikhadufinew@gmail.com
}

\begin{abstract}
Abstrak. Penukar kalor tipe shell and tube merupakan salah satu komponen alat destilasi minyak atsiri cengkeh menggunakan uap panas sebagai fluida panas dan air sebagai fluida dingin dimana masing-masing mengalir secara berlawanan. Sistem destilasi yang ada di lapangan masih menggunakan kondensor atau penukar kalor pipa lurus, dimana temperatur fluida panas yang keluar masih dinilai cukup tinggi sehingga indikasi efektivitas belum optimal. Untuk mengoptimalkan efektivitas, maka didesain penukar kalor shell and tube dengan metode numerik berbasis CFD Fluent menggunakan geometri pipa hexagonal pada layout tube $30^{\circ}, 60^{\circ}, 45^{\circ}$, dan $90^{\circ}$ susunan inline dan staggered dan jenis aliran berlawanan. Penelitian ini memvariasikan laju aliran massa dingin $\left(\dot{\mathrm{m}}_{\mathrm{c}}\right)=0,052 ; 0,059 ; 0,083 ; 0,1 ; 0,12 \mathrm{Kg} / \mathrm{s}$, sedangkan laju aliran massa fluida panas konstan. Hasil penelitian simulasi diperoleh efektivitas maksimal terjadi pada laju aliran massa $0,052 \mathrm{~kg} / \mathrm{s}$ sebesar 5,45\% layout susunan staggerred dan minimum terjadi pada laju aliran massa sebesar $0,12 \mathrm{~kg} / \mathrm{s}$ sebesar $4,01 \%$ pada layout susunan inline. Hasil penilitian ini pun diharapkan bisa membantu masyarakat yang dapat digunakan untuk berbagai minyak atsiri.
\end{abstract}

Kata kunci: Shell and tube, efektivitas, minyak cengkeh, layout, geometri hexagonal.

\begin{abstract}
Shell and tube type heat exchanger is a component of clove essential oil distillation apparatus using hot steam as hot fluid and water as cold fluid, each flowing in opposite directions. The distillation system in the field still uses a condenser or straight pipe heat exchanger, where the temperature of the hot fluid that comes out is still considered high enough so that the indication of effectiveness is not optimal. To optimize the effectiveness, a shell and tube heat exchanger is designed with a numerical method based on Fluent CFD using a hexagonal pipe geometry in tube layouts of $30^{\circ}$, $60^{\circ}, 45^{\circ}$, and $90^{\circ}$ inline and staggered arrangement and counter flow type. This study varied the cold mass flow rate $(\dot{m c})=0.052 ; 0.059 ; 0.083 ; 0.1 ; 0.12 \mathrm{Kg} / \mathrm{s}$, while the mass flow rate of the hot fluid is constant. The simulation results obtained that the maximum effectiveness occurred at a mass flow rate of $0.052 \mathrm{~kg} / \mathrm{s}$ of $5.45 \%$ staggerred layout and the minimum occurred at a mass flow rate of $0.12 \mathrm{~kg} / \mathrm{s}$ of $4.01 \%$ on an inline layout. The results of this research are also expected to help the community which can be used for various essential oils.
\end{abstract}

Keywords: Shell and tube, effectiveness, clove oil, layout, hexagonal geometry.

\section{PENDAHULUAN}

Minyak cengkeh berasal dari tanaman engkeh (Eugenia aromaticum) baik dari bunga, daun, dan gagang atau tangkai cengkeh [1]. Minyak cengkeh merupakan salah satu minyak atsiri yang dibutuhkan pada berbagai industri seperti industri 
kosmetik [2], obat-obatan [3], makanan dan minuman [4], dan bahan aditif bahan bakar minyak [5]. Minyak atsiri tanaman cengkeh terdapat pada bunga (10-20\%), gagang atau tangkai (5-10\%) dan daun (1-4\%) [6]. Komponen yang terdapat dalam minyak atsiri cengkeh adalah eugenol $70-80 \%$.

Umumnya proses destilasi minyak atsiri menggunakan metode dikukus (water and steam distillation), dimana komponen-komponen destilasi terdiri dari ketel, kondensor, pipa kondensor (pipa pendingin), tangki pendingin, separator, dehidrator dan penampung minyak [1].

Kondensor merupakan salah satu tipe penukar kalor yang diklasifikasin berdasarkan fungsi proses dimana satu aliran uap kondensasi dan aliran lainnya sebagai udara pendingin (air atau udara) [7]. Penukar kalor dapat meningkatkan efisiensi produksi industri dan memastikan keamanan peralatan, diantaranya tipe shell and tube telah banyak digunakan dalam berbagai aplikasi industri, seperti sistem tenaga, industri energi, pendinginan, ventilasi pemanas dan pendinginan udara (HVAC), dan pengolahan makanan [8-12].

Sistem destilasi yang ada di lapangan masih menggunakan kondensor atau penukar kalor pipa straight atau pipa lurus. Salah satu kekurangan dari kondensor pipa straight yaitu nilai temperatur fluida panas yang keluar masih dinilai cukup besar sehingga mengindikasikan bahwa efektivitas kondensor belumlah optimal dan sesuai dengan hasil penelitian [13-16].

Berbagai penelitian terkait sistem destilasi minyak atsiri diantaranya; destilasi uap bertekanan minyak atsiri dari daun cengkeh [17], peningkatan rendemen minyak atsiri daun cengkeh dengan metode deglifikasi dan fermentasi menggunakan destilasi uap [18], laju kondensasi destilasi minyak atsiri cengkeh [19], dan pengaruh beban panas pada destilasi minyak atsiri cengkeh [20]. Selain itu penelitian terkait kondensor shell and tube, diantaranya; perbandingan model geometri tube bulat, tube kotak, tube kotak dengan fillet dan tube hexagonal terhadap laju perpindahan panas [21], analisis jumlah tube dan dan diameter shell untuk mendapat desain kondensor optimal [22], efek tube layout pada performance penukar kalor shell and tube [23]. Nampak bahwa berbagai penelitian di atas belum adan informasi terkait penerapan penukar kalor shell and tube pada kondensor minyak atsiri.

Untuk mengoptimalkan efektivitas kondensor minyak atsiri cengkeh dengan tipe shell and tube horizontal, maka parameter yang berpengaruh antara lain; layout tube, model geometri tube, laju aliran massa fluida sisi shell, tipe aliran [21-24].

Fokus utama penelitian ini adalah memberikan wawasan yang bermanfaat tentang karakteristik perpindahan kalor dan aliran dari penukar kalor shell and tube akibat memvariasikan laju aliran massa fluida dingin pada sisi shell dengan model geometri tube hexagonal pada layout tube susunan staggered dan jenis aliran berlawanan.

\section{METODE PENELITIAN}

\subsection{Rancangan Penelitian dan Prosedur Penelitiain}

Adapun perancangan pada alat yang diperlukan untuk melakukan penelitian terlihat sebagai berikut:
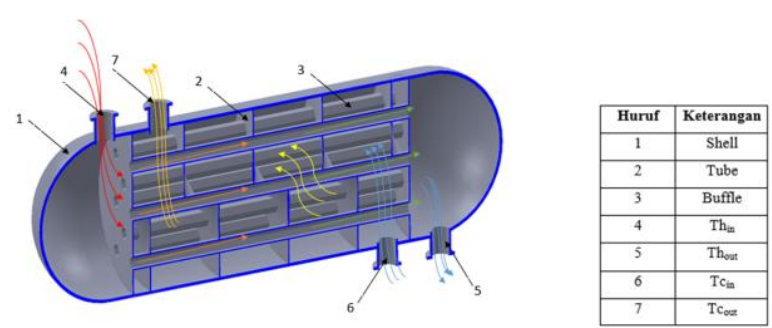

Gambar 1. Model penukar kalor counter flow.

Dalam melaksanakan penelitian ini diguanakan metode dan langkah - langkah sehingga tujuan dari penelitian yang dilakukan dapat sesuai dengan apa yang diharapkan.

1. Pembuatan model design dengan solidworks 2016.

2. Pembuatan Mesh.

3. Pre Processing.

a. Diagram alir simulasi pada CFD

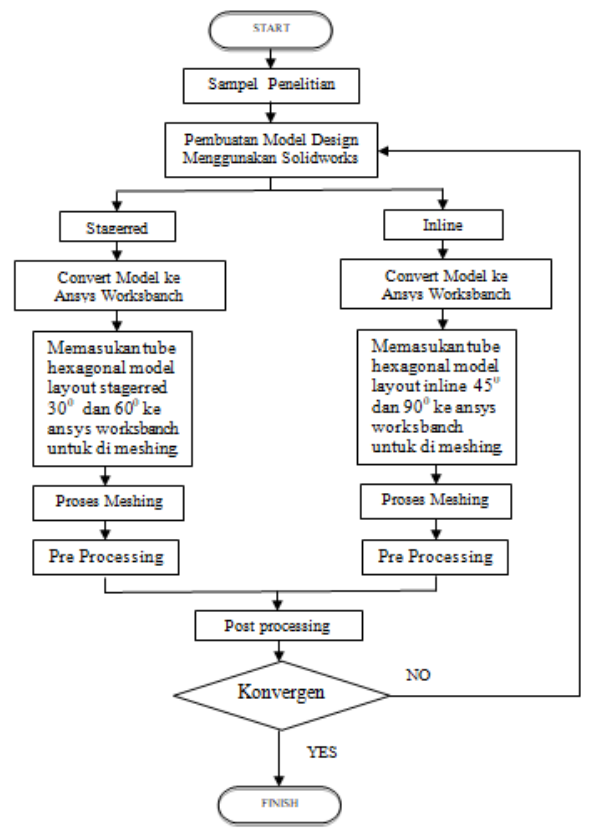

Gambar 2. Diagram alir simulasi CFD aliran counter flow 


\section{b. Persamaan Diskritisasi}

Diskritisasi pada simulasi ANSYS diinterpretasikan dengan pembentukan mesh atau grid. Ukuran mesh yang diterapkan pada model akan mempengaruhi ketelitian analisis CFD. Semakin kecil ukuran mesh pada model, maka hasil yang didapatkan akan semakin teliti namun membutuhkan daya komputasi dan waktu yang lebih lama dibandingkan dengan mesh yang memiliki ukuran lebih besar.

c. Indepedensi Grid

Tabel 1. Grid Indepedensi

\begin{tabular}{lcc}
\hline Geometri/Part & $\begin{array}{c}\text { Jenis } \\
\text { Meshing }\end{array}$ & $\begin{array}{c}\text { Jumlah } \\
\text { Elemen }\end{array}$ \\
\hline Shell/part1 & Tetrahedron & 24.102 \\
Tube/part2 & Tetrahedron & 34.502 \\
Buffle/part3 & Tetrahedron & 14.902 \\
\hline \multicolumn{2}{c}{ Total Elemen } & 73.506 \\
\hline
\end{tabular}

d. Pengisian Data Material

Tabel 2. Material Propertis minyak atsiri cengkeh.

\begin{tabular}{clcc}
\hline No. & \multicolumn{1}{c}{ Properties } & Nilai & Satuan \\
\hline 1 & Densitas, $\rho$ & 836 & $\mathrm{Kg} / \mathrm{m} 3$ \\
2 & Panas spesifik, Cp & 2250 & $\mathrm{~J} / \mathrm{kg} . \mathrm{K}$ \\
3 & Konduktivitas & 0.136 & $\mathrm{~W} / \mathrm{m} . \mathrm{K}$ \\
& termal, K & & \\
4 & Viskositas, $v$ & 0.17 & $\mathrm{Kg} / \mathrm{m} . \mathrm{s}$ \\
\hline
\end{tabular}

Tabel 3. Material Propertis air.

\begin{tabular}{clcc}
\hline No. & \multicolumn{1}{c}{ Properties } & Nilai & Satuan \\
\hline 1 & Densitas, $\rho$ & 998.2 & $\mathrm{Kg} / \mathrm{m} 3$ \\
2 & Panas spesifik, Cp & 4182 & $\mathrm{~J} / \mathrm{kg} . \mathrm{K}$ \\
3 & Konduktivitas & 0.6 & $\mathrm{~W} / \mathrm{m} . \mathrm{K}$ \\
& termal & & \\
4 & Viskositas & 0.001003 & $\mathrm{Kg} / \mathrm{m} . \mathrm{s}$ \\
\hline
\end{tabular}

4. Postprocessing

a. Residual Monitoring

Tabel 4. Parameter Monitoring

\begin{tabular}{clc}
\hline No & Parameter (satuan) & $\begin{array}{c}\text { Kriteria } \\
\text { Konvergen }\end{array}$ \\
\hline 1 & Energy & 0.001 \\
2 & Kecepatan-x $(\mathrm{m} / \mathrm{s})$ & 0.1 \\
3 & Kecepatan-y $(\mathrm{m} / \mathrm{s})$ & 0.1 \\
4 & Kecepatan-z $(\mathrm{m} / \mathrm{s})$ & 0.1 \\
5 & k-epsilon & 0.1 \\
\hline
\end{tabular}

b. Proses Iterasi

c. Viewing Result

Layout 60 derajat Counter Flow. a. laju aliran massa $=0.052 \mathrm{~kg} / \mathrm{s}$.

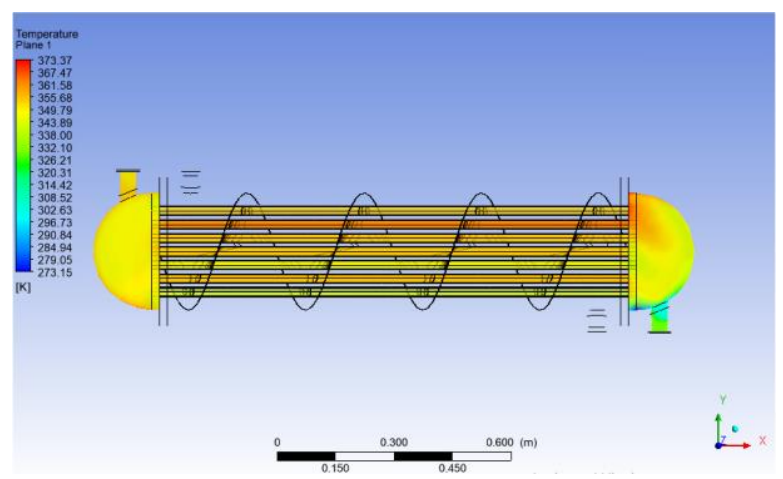

a) Tube

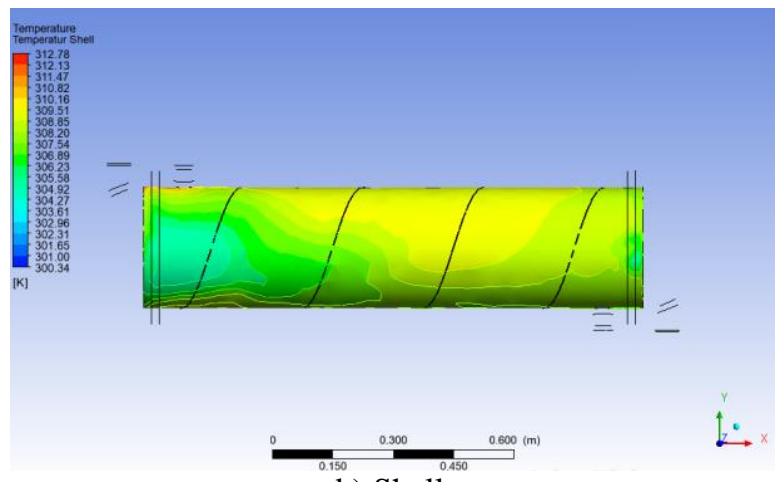

b) Shell

Gambar 3. Contour temperatur penukar kalor

a) Tube, b) Shell.

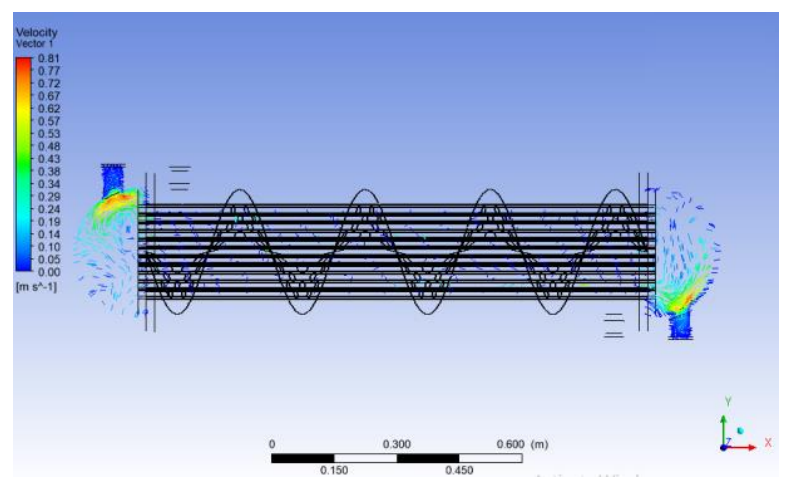

a) Tube

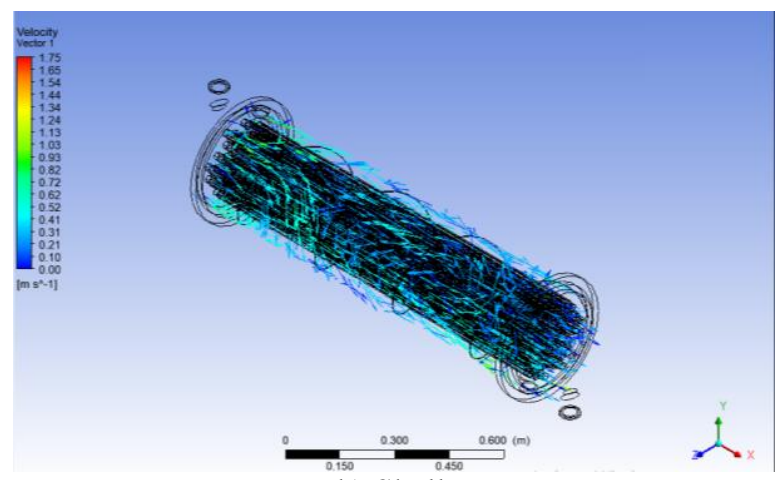

b) Shell

Gambar 4. Contour kecepatan penukar kalor a) Tube, b) Shell. 


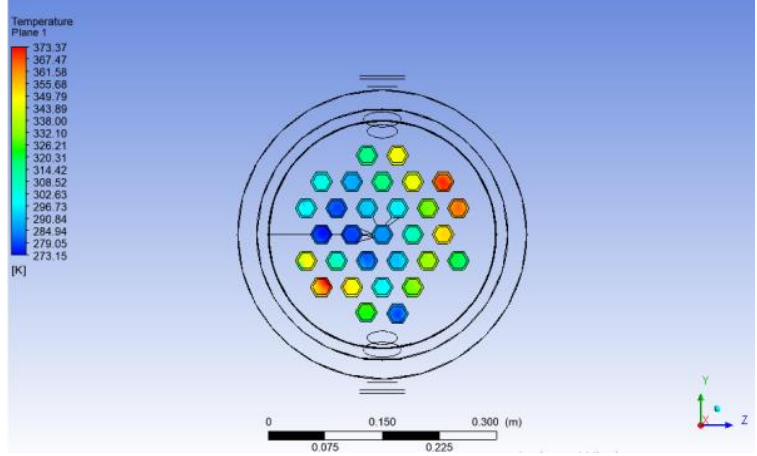

a) Span 0 meter

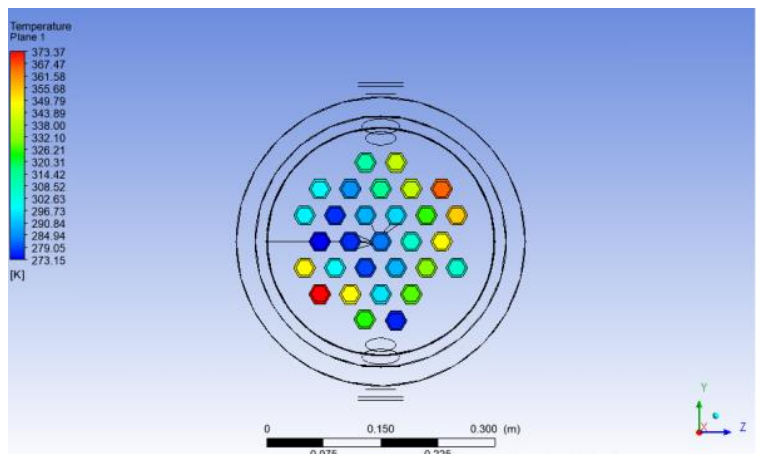

b) Span 0.4 meter

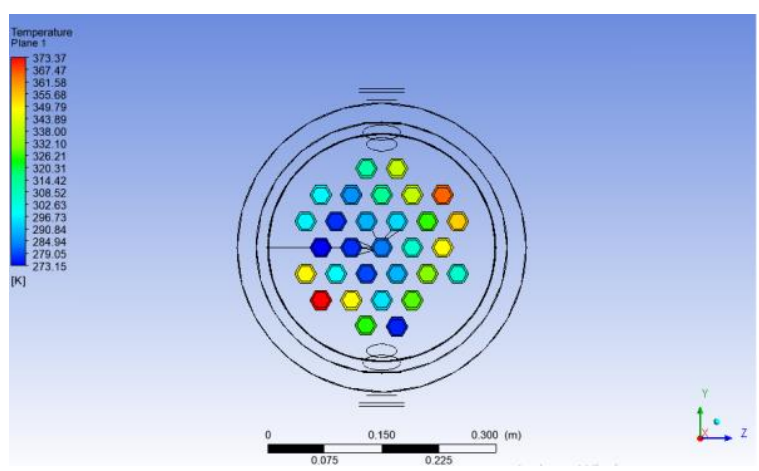

c) Span 0.8 meter

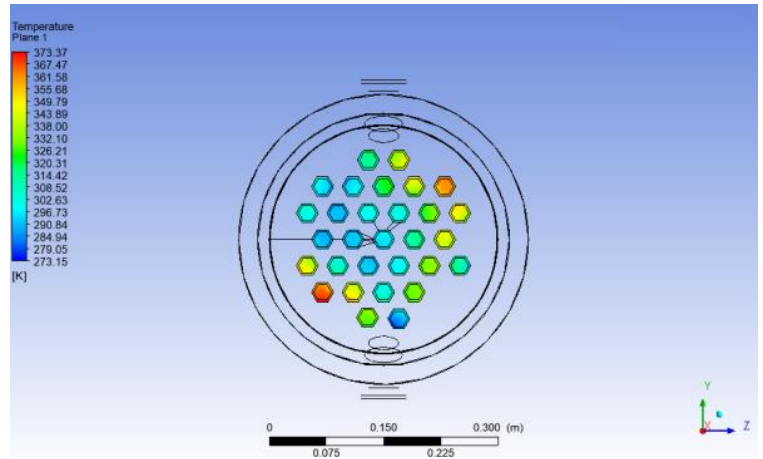

d) Span 1.2 meter

Gambar 5. Contour temperatur penukar kalor pada a) span 0.8 meter, b) span 0.4 meter c) span 0.8 meter d) span 1.2 meter.

\subsection{Validasi Model Numerik}

Validasi adalah penentuan apakah mode konseptual simulasi (sebagai tandingan program komputer) adalah representasi akurat dari sistem nyata yang sedang dimodelkan (Law dan Kelton, 1991). Ada beberapa model validasi diantaranya, model konseptual, model logika, dan model komputer atau simulasi. Dalam penelitian ini model menggunakan simulasi komputer. Verifikasi model komputer dapat dilakukan dengan :

- Metode pemograman terstuktur

- Penulusuran model simulasi

- Pengujian relasi logis

- Verifikasi dengan model analisis

- Verifikasi menggunakan grafik

Berikut gambar grafik validasi laju aliran massa hasil penelitian terdahulu dengan penelitian yang dilakukan menggunakan simulasi disatukan dalam satu grafik untuk melihat keselarasan garafik heat transfer kedua kurva tersebut.

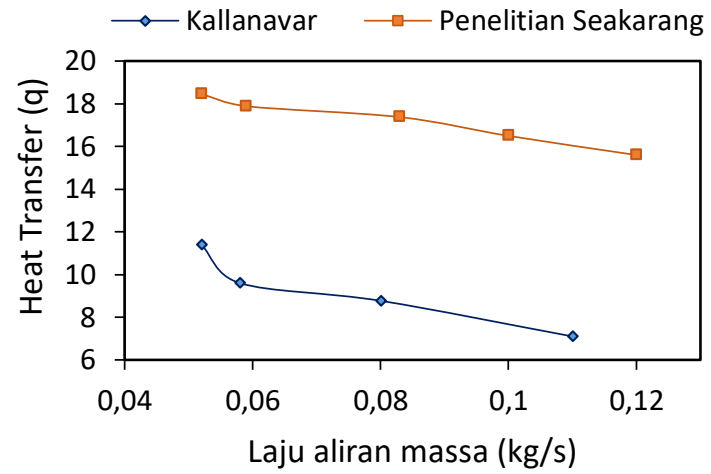

Gambar 6. Grafik validasi kurva laju aliran massa fluida dingin.

Gambar 6 memperlihatkan kurva grafik berwarna merah merupakan hasil dari penelitian yang dilakukan menggunakan metode simulasi komputer, sedangkan yang berwarna biru merupakan hasil dari penelitian kallanavar yang dilakukan menggunakan metode eksperimen terdahulu. Kedua penelitian ini menggunakan fluida dingin yang sama yaitu air. Dengan laju aliran massa yang diberikan sama tetapi memberikan hasil nilai heat transfer keduanya berbeda atau berjauhan seperti dapat kita lihat pada grafiknya, hal ini terjadi akibat perbedaan material yang digunakan pada keduanya, untuk eksperimen yang menggunakan material copper (tembaga) sedangkan pada simulasi menggunakan material pipa aluminium.

\section{HASIL DAN PEMBAHASAN}

Dari data-data yang diperoleh baik dari hasil simulasi yang sudah dilakukan pada penukar kalor dan dengan memberikan variasi pada laju 
aliran massa fluida dingin pada shell $\left(\dot{m}_{c}\right)=$ 0,$052 ; 0,059 ; 0,083 ; 0,1 ; 0,12 \mathrm{~kg} / \mathrm{s}$, untuk mendapatkan efektivitas $(\varepsilon)$ terhadap masing masing variasi dari $30^{\circ} ; 60^{\circ} ; 45^{\circ}$ dan $90^{\circ}$ disajikan dalam tabel 5.

Tabel 5. Perhitungan efektivitas.

\begin{tabular}{|c|c|c|c|}
\hline \multicolumn{2}{|c|}{ Layout tube $\left(^{\circ}\right)$} & $\dot{\mathrm{m}}_{\mathrm{c}}(\mathrm{kg} / \mathrm{s})$ & $\varepsilon(\%)$ \\
\hline \multirow{10}{*}{ Staggered } & 30 & 0.052 & 5.35 \\
\hline & 30 & 0.059 & 5.20 \\
\hline & 30 & 0.083 & 5.07 \\
\hline & 30 & 0.1 & 4.81 \\
\hline & 30 & 0.12 & 4.48 \\
\hline & 60 & 0.052 & 5.45 \\
\hline & 60 & 0.059 & 5.28 \\
\hline & 60 & 0.083 & 5.13 \\
\hline & 60 & 0.1 & 4.87 \\
\hline & 60 & 0.12 & 4.61 \\
\hline \multirow{10}{*}{ Inline } & 45 & 0.052 & 4.77 \\
\hline & 45 & 0.059 & 4.73 \\
\hline & 45 & 0.083 & 4.58 \\
\hline & 45 & 0.1 & 4.29 \\
\hline & 45 & 0.12 & 4.01 \\
\hline & 90 & 0.052 & 4.89 \\
\hline & 90 & 0.059 & 4.85 \\
\hline & 90 & 0.083 & 4.65 \\
\hline & 90 & 0.1 & 4.35 \\
\hline & 90 & 0.12 & 4.12 \\
\hline
\end{tabular}

Hasil simulasi dengan memvariasikan laju aliran massa $\left(\dot{m}_{c}\right)=0.052,0.059 .0 .083,0.1,0.12$ $\mathrm{kg} / \mathrm{s}$, dan layout tube yaitu $30^{\circ} ; 60^{\circ} ; 45^{\circ}$ dan $90^{\circ}$. Memperlihatkan bahwa semakin besar laju aliran massa pada fluida dingin efektivitas $(\varepsilon)$ semakin menurun seperti terlihat pada gambar berikut :

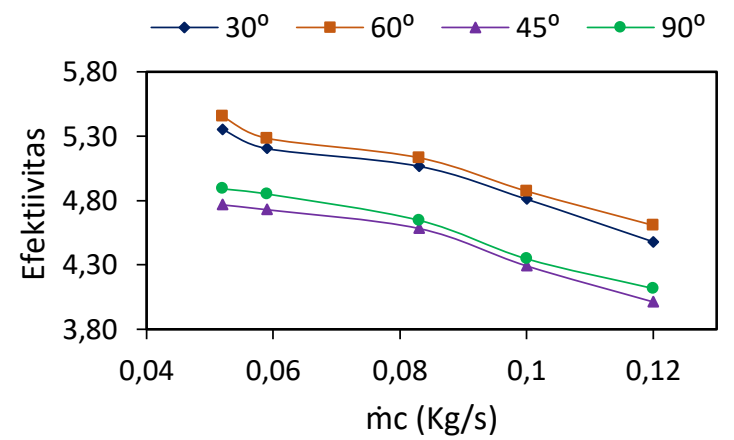

Gambar 7. Grafik efektivitas $(\varepsilon)$ pada berbagai laju aliran massa fluida dingin.

Grafik Efektivitas $(\varepsilon)$ menunjukan titik maksimum terjadi pada laju aliran massa 0.052 $\mathrm{kg} / \mathrm{s}$ untuk layout $60^{\circ}$ yaitu 5.45 mengikuti persamaan $(\varepsilon)$. Kemudian diikuti dengan tren grafik yang menurun setelah diberikan laju aliran massa, hal ini terjadi karena saat diberikan laju aliran massa fluida dingin yang kecil, proses perpindahan panas mengakibatkan penyerapan temperatur yang masuk oleh air lebih banyak sehingga mengakibatkan penurunan temperatur uap cengkeh yang awalnya tinggi menjadi rendah, sebaliknya dengan diberikannya laju aliran massa yang besar proses perpindahan panas yang terjadi membuat temperatur keluaran rendah yang membuat penurunan pada efektivitas $(\varepsilon)$.

$$
\varepsilon=\frac{Q_{\text {aktual }}}{Q_{\max }} \times 100 \%
$$

\section{KESIMPULAN}

Berdasarkan hasil penelitian simulasi dengan memvariasikan laju aliran massa fluida dingin diperoleh bahwa efektivitas penukar kalor shell and tube mengalami penuruan dengan bertambahnya laju aliran massa fluida dingin. Efektivitas maksimum terdapat pada laju aliran massa sebesar $0,052 \mathrm{~kg} / \mathrm{s}$ sebesar $5,45 \%$ pada layout $60^{\circ}$ susunan stagerred dan terkecil terdapat pada laju aliran massa sebesar $0,12 \mathrm{~kg} / \mathrm{s}$ sebesar $4,01 \%$ pada layout $45^{\circ}$ susunan inline. Dari hasil penelitian juga bahwa susunan staggerred memberikan perpindahan panas yang lebih baik dari susunan inline, hal ini dapat dilihat dari hasil efektivitas yang dihasilkan lebih baik yaitu pada layout susunan staggerred.

\section{DAFTAR PUSTAKA}

[1] L. Pratiwi, M. Rachman, and N. Hidayati, "Ektraksi Minyak Atsiri Dari Bunga Cengkeh Dengan Pelarut Etanol Dan NHeksana," The $3^{\text {rd }}$ University Research Colloquium, pp. 655-661, 2016.

[2] M. Dreger and K. Wielgus, "Application of essential oils as natural cosmetic preservatives," vol. 59, no. 4, 2013, doi: 10.2478/hepo-2013-0030.

[3] A. Anita, S. Khotimah, and A. H. Yanti, "Aktivitas Antibakteri Ekstrak Daun Benalu Jambu Air (Dendropthoe pentandra (L.) Miq) Terhadap Pertumbuhan Salmonella typhi," Protobiont, vol. 3, no. 2, pp. 268-272, 2014.

[4] J. Grush, D. L. . Noakes, and R. . Moccia, "The Efficacy of Clove Oil As An Anesthetic for the Zebrafish, Danio rerio (Hamilton)," vol. 1, no. 1, pp. 46-53, 2004.

[5] A. T. Lawang, D. Setyaningsih, and M. Syahbana, "Evaluasi Minyak Daun Cengkeh dan Minyak Sereh Wangi Sebagai Bioaditif Bahan Bakar Solar Dalam Menurunkan Emisis Gas Buang Pada Mesin Diesel," Teknol. Pertan., vol. 20, no. 2, pp. 95-102, 2019. 
[6] N. Nurdjannah, "Diversifikasi Penggunaan Cengkeh," Perspektif, vol. 3, no. 2, pp. 6170.

[7] R. K. Shah and D. P. Sekulic, Fundamentals of Penukar kalor Design. John Wiley \& Sons, Inc, 2003.

[8] S. Chingulpitak and S. Wongwises, "A comparison of flow characteristics of refrigerants flowing through adiabatic straight and helical capillary tubes," Int. Commun. Heat Mass Transf., vol. 38, no. 3, pp. 398-404, 2011, doi: 10.1016/j.icheatmasstransfer.2010.12.014.

[9] P. K. Sahoo, M. I. A. Ansari, and A. K. Datta, "A computer based iterative solution for accurate estimation of heat transfer coefficients in a helical tube penukar kalor," J. Food Eng., vol. 58, no. 3, pp. 211-214, 2003, doi: 10.1016/S0260-8774(02)00370-9.

[10] W. H. Park and C. K. K. Yang, "Effects of using advanced cooling systems on the overall power consumption of processors," IEEE Trans. Very Large Scale Integr. Syst., vol. 21, no. 9, pp. 1644-1654, 2013, doi: 10.1109/TVLSI.2012.2217386.

[11] H. Ma et al., "Assessment of the optimum operation conditions on a heat pipe penukar kalor for waste heat recovery in steel industry," Renew. Sustain. Energy Rev., vol. 79, no. April, pp. 50-60, 2017, doi: 10.1016/j.rser.2017.04.122.

[12] K. Chen, Y. Chen, Y. She, M. Song, S. Wang, and L. Chen, "Construction of effective symmetrical air-cooled system for battery thermal management," Appl. Therm. Eng., vol. 166, p. 114679, 2020, doi: 10.1016/j.applthermaleng.2019.114679.

[13] B. A. Bhanvase, S. D. Sayankar, A. Kapre, P. J. Fule, and S. H. Sonawane, "Experimental investigation on intensified convective heat transfer coefficient of water based PANI nanofluid in vertical helical coiled penukar kalor," Appl. Therm. Eng., vol. 128, pp. 134-140, 2018, doi: 10.1016/j.applthermaleng.2017.09.009.

[14] S. M. Hashemi and M. A. AkhavanBehabadi, "An empirical study on heat transfer and pressure drop characteristics of $\mathrm{CuO}$-base oil nanofluid flow in a horizontal helically coiled tube under constant heat flux," Int. Commun. Heat Mass Transf., vol. 39, no. 1, pp. 144-151, 2012, doi: 10.1016/j.icheatmasstransfer.2011.09.002.

[15] N. Ghorbani, H. Taherian, M. Gorji, and H. Mirgolbabaei, "Experimental study of mixed convection heat transfer in vertical helically coiled tube penukar kalors," Exp. Therm. Fluid Sci., vol. 34, no. 7, pp. 900 905, 2010, doi: 10.1016/j.expthermflusci.2010.02.004.

[16] M. Majid Etghani and S. Amir Hosseini Baboli, "Numerical investigation and optimization of heat transfer and exergy loss in shell and helical tube penukar kalor," Appl. Therm. Eng., vol. 121, pp. 294-301, 2017, doi: 10.1016/j.applthermaleng.2017.04.074.

[17] Jayanudin, "Komposisi kimia minyak atsiri daun cengkeh dari proses penyulingan uap," Tek. Kim. Indones., vol. 10, no. 1, pp. 37-42, 2011.

[18] C. Wijaya, A. Jayuska, and A. H. Alimuddin, "Peningkatan Rendemen Minyak Atsiri Daun Cengkeh (Syzygium aromaticum) Dengan Metode Delignifikasi dan Fermentasi," vol. 4, no. 4, pp. 15-20, 2015.

[19] R. Waelauruw, Analisis Laju Kondensasi Akibat Pengaruh Beban Panas dan Massa Gagang Cengkeh Terhadap Karakteristik Perpindahan Panas Pada Destilasi Minyak Atsiri. Fakultas Teknik Universitas Pattimura, 2016.

[20] N. Titahelu, Analisis Pengaruh Masukan Panas Terhadap Karakteristik Proses Destilasi Minyak Atsiri Cengkeh (Syzygium aromaticum), April. 2019.

[21] A. P. Shinde, M. L. Shinde, S. S. Yadav, M. R. Surve, A. S. Futane, M. Bhaumik, "Performance Analysis of Penukar kalor using CFD“, International Journal of Innovative Research in Science engineering and Techonogy., vol 7(3), pp: 3053-3063, 2018 , doi: 10.15680/IJIRSET.2018.0703072.

[22] Sobar Ihsan, 2017. Perencanaan dan analisa perhitungan jumlah tube dan diameter shell pada kondensor berpendinginan air pada sistem refrigerasi NH3, Jurnal Teknologi Proses dan Inovasi Industri, Vol. 2 (1), pp:13-17, 2017.

[23] S. Kallannavar, S. Mashyal, M. Rajangale, Effect of tube layout on the performance of shell and tube penukar kalors, Material Today: Proceedings, PP:1-5, 2019, doi:10.1016/j.matpr.2019.10.151

[24] Avinash P. Shinde, Mahadev L. Shinde, Sagar S. Yadav, Manasvi R. Surve, A. S. Futune, Mainak Bhaumik., 2018. "Perfomance Analysis of Penukar kalor using CFD", Mechanical Enginering, Navi Mumbai, India. 